\title{
Informal networks and what they mean for anti-corruption practice
}

\author{
Claudia Baez Camargo, Head of Public Governance Jacopo Costa, Senior Research Fellow \\ Saba Kassa, Public Governance Specialist
}

\section{Abstract}

Corruption is frequently associated with money alone and the behaviours of a few individual "bad apples" operating in otherwise healthy governance systems. This is too simplistic. As the latest research shows, including research in Tanzania and Uganda on which this Policy Brief is based, ${ }^{1}$ corruption is a networked phenomenon. This Policy Brief explains what this means and its implications for anti-corruption practice.

When ordinary citizens and business people face problems, like constrained access to public services or an uneven playing field, they invest time, effort and resources in building informal networks. Held together by personal connections and corrupt payments, these informal networks are a problem-solving mechanism. They allow members - such as business people, other citizens and public officials - to pursue a variety of goals. The networks aid in easing access to public services, for example, or helping a business to run smoothly, or securing business opportunities with the government. Informal networks can be leveraged to speed up long and complicated permit processes or exploit weaknesses in formal tender processes to obtain undue access to contracts. When red tape is used by public officials to extort bribes from service users, informal networks can help manage and overcome these demands.
In contexts in which these informal networks are widespread, the research shows that conventional anti-corruption measures, such as introducing more regulations, policies and controls, can actually backfire and increase corruption.

Breaking this reinforcing cycle of networked corruption requires a shift in thinking and approaches:

1. Focusing on networked corruption as opposed to individual corrupt behaviours.

2. Tackling corruption both from the demand and the supply side by addressing inefficiencies and weaknesses in public systems that cause problems for ordinary citizens and business people. This may make it less likely that they will resort to corruption through informal networks to overcome the public service weaknesses.

3. Harnessing informal networks for anticorruption objectives. This includes leveraging new insights into social norms and networks and establishing Collective Action initiatives to better target the underlying drivers of corruption.

Baez Camargo, C., Costa, J \& L. Koechlin (2021) Informal networks as investment in East Africa. Global Integrity Anti-Corruption Evidence Programme (GI-ACE), https://baselgovernance.org/publications/informal-networks-investment-east-africa 


\section{Understanding corruption with a network lens}

New research is making it increasingly clear that anti-corruption practitioners need to pay more attention to networks, not only corrupt behaviours of individuals. Often corrupt behaviour takes place according to unwritten rules and through informal networks that connect the public and private sectors. In short, corruption is a networked phenomenon and takes places in the shadows of informality.

Our research on the functioning of informal networks in East Africa, based on evidence collected in Tanzania and Uganda, illuminates exactly this. The research presents evidence, consisting of 10 mini case studies, ${ }^{2}$ that describe informal networks associated with bribery and procurement fraud.

The case studies illustrate ways in which ordinary citizens and business people ${ }^{3}$ invest significant efforts in building informal networks to overcome shortcomings in public service delivery and to access business opportunities. Monetary bribes and associated benefits are essential to developing informal networks with public officials. Importantly, informal networks may go beyond simply friends and acquaintances.

\section{Informal networks as problem-solving mechanisms}

The research shows that ordinary citizens and business people build networks as a strategic tool to "get things done" with and within government departments. The drivers of this behaviour are complex. Citizens and business owners may struggle to access public services due to various resource constraints. Red tape compounds this, reflected in complex procedures

2 Six from Tanzania and four from Uganda.

3 By "citizens", we mean individuals who interact with public services for private reasons, for example to obtain a driving licence. By "business people", we mean individuals who interact with public services for business purposes, for example to obtain a business licence or bid for a government contract. Of course, the two categories overlap. and vague regulations that public officials can easily exploit. For instance, business owners who lack the right network and do not give into requests for bribes often get informally blacklisted in public contracting.

Harnessing informal networks can be an effective strategy to manage, circumvent or capitalise on the weaknesses in public service provision to solve a problem. The case studies offer examples of how networks are used to:

- Ease access to public services: Informal networks can aid citizens in using personal connections to skip red tape or speed up a service to which they are officially entitled but may otherwise be delayed. At a more pernicious level, informal networks can help users to obtain services they are not entitled to, or manipulate processes to their advantage.

\section{- Secure business opportunities with government:} Informal networks can aid in derailing competitive procurement processes. Business people who have built strong informal networks and have insider contacts within government departments may only need to pay the "fee" (bribes and/or kickbacks) their contacts ask for in order to be awarded public contracts. Informal networks can also facilitate privileged access to information about tenders.

- Help businesses run smoothly: Informal networks can aid in leapfrogging the many bureaucratic hurdles faced when establishing and running businesses. Complex networks can be built to solve seemingly simple problems. Business people may build bribery networks to secure a competitive advantage over other firms, to avoid sanctions and to obtain permits and licences swiftly. 
The research shows that while these networks are informal, they are surprisingly well organised. Different members of the networks fulfil essential roles, identified as:

- Seekers: citizens and business people who want to connect with a public official

- Doers: public officials who can provide an undue favour to a service seeker

When the network becomes more complex, other roles emerge within the networks, identified as:

- Brokers: connect the "seekers" with the "doers"

- Facilitators: public officials that help "seekers" and "doers" navigate complex office bureaucracies

- Intermediaries: represent the networks of insiders in public institutions vis-à-vis seekers and brokers

- Instigators: orchestrate elaborate corrupt schemes

How exactly they are organised depends on what goals the networks mainly seek to achieve. Some operate via predominantly extortive dynamics, as in the case of the public official who threatens to "disappear" a file unless a bribe is given. Others are more collusive, ${ }^{4}$ where public- and private-sector actors conspire to execute an illicit deal that is mutually beneficial. Naturally, some networks have hybrid features.

Key is that the networks link up the demand and the supply for informal transactions. The currency that lubricates the networks is corruption and other forms of monetary exchange, such as gift giving.

The research shows that even when a contact can be established by virtue of existing social relationships, building and nurturing connections more often than not involves the payment of bribes. For new relationships, the costs are higher. Either way, the bribe serves both as

4 Targeting collusive networks involve sharpening detection mechanisms and skills. A key challenge for anti-corruption practitioners is to devise whistleblowing mechanisms that take into account social pressures and expectations. an initial incentive to link up the necessary agents and actions, and to cement relations and actions. Corruption is thus essential to incentivise, establish and stabilise connections and networks. Building a network comes at a cost, but the ordinary citizens and business people in our research clearly consider it a prudent investment to help them obtain services, profitable opportunities or illicit favours.

\section{Networked corruption: implications for anti-corruption practice}

Why is the self-reinforcing networked nature of corruption a problem?

First, because informal networks evolve and can strengthen over time. The research shows that exchanging a bribe is not just a one-off monetary transaction. Corrupt exchange is used to establish and thereafter to nourish social connections. In short, corruption is not just about money. It is a way to build and strengthen social capital, reflected in having the right networks.

Second, because in a context where informality prevails, adding more formal controls and accountability mechanisms such as audits and regulations may actually generate more corruption. More controls mean more people need to be co-opted and bribed. More controls add another layer of complexity over the existing tangle of red tape.

Third, because those who lack the right social connections or money are further excluded in the public sphere. In such a context, it is the poor that are further marginalised. While informal networks thrive on solidarity and reciprocity, the sum of these kind of networks drives privileged or undue access to public resources. This hurts the weak in the society, including citizens or small businesses.

Fourth, using informal networks to overcome or exploit weaknesses in formal systems erodes the basic principles that should undergird public service provision. Preferential access to public services and 
the award of public contracts are reinforced. In the long run, everyone loses out due to ever-weaker provision of public services and public contracts that do not go to the best bidder.

Fifth, the strategic use of informal networks as a problem-solving mechanism normalises stereotypes that government departments are weak and reinforces corruption as the expected behaviour. Service users, such as ordinary citizens and business people, assume that without some informal help it is not possible to obtain good quality, timely public services or to compete on a level playing field for public contracts.

\section{Breaking the cycle: designing anti-corruption interventions with}

\section{a network lens}

\section{Addressing key hurdles in public office}

Addressing the hurdles that citizens and business people experience or capitalise on while accessing public services and competing in public contracts should be a central element of an informed anti-corruption approach. A focus on problem solving is important to reduce incentives to build informal networks through corruption and other forms of monetary exchange. Giving citizens and business owners alternative, non-corrupt solutions to their problems can reduce the functionality of informal networks and squarely target the motivations of the actors who engage in bribery and other illicit practices.

Practical actions include:

- Addressing red tape by improving and simplifying procedures to access public service reduces the incentives to connect to or develop a network. ${ }^{5}$
- Strengthening initiatives and programmes aimed at improving the ease of doing business. Simplifying procedures to open a business, obtain construction and other permits, access electricity, register property and pay taxes would tackle key challenges that business people are often confronted with. ${ }^{6}$

- Decreasing discretionary decision-making through formal public-sector reforms and their effective implementation. Reforms can include streamlined decision-making processes and standard operating procedures (SOPs), egovernment solutions, increased transparency as well as smarter monitoring mechanisms. These formal measures are often already in place, but lack decisive and effective implementation.

- Complementing formal controls with an emphasis on outputs (contract implementation) and the use of public service scorecards. An output and results-based approach focuses, for example, on the manner in which public contractors deliver on their projects or on the monitoring of delivery of public services. These approaches might be a better proxy to detect corruption and to bring duty bearers to account, as opposed to increasing the formal rules.

- Formalising informal practices of payments to access public services. The aim of this strategy is to institutionalise the logic and principles of illicit exchange into the formal processes of the public administration. Instead of paying a bribe, the service users can pay a fee that gives them the opportunity to access preferential services. ${ }^{7}$ This means creating a valuable and credible formal alternative to investing in corruption and informal networks.

5 The case of Rwanda is a good example of how when systems are reformed and invested in to ensure that service seekers can enjoy quality public services without long queues, informal networks lose relevance. Baez-Camargo, Claudia, Tharcisse Gatwa, Abel Dufitumukiza, Cosimo Stahl, and Saba Kassa. 2017. "Behavioural influences on attitudes towards petty corruption: A study of social norms, automatic thinking and mental models in Rwanda." Basel Institute on Governance.

6 Steps have been taken in Tanzania to offer "one stop shop" public service solutions and to digitalise payments and other transactions which hold promise to reduce the administrative burden for users.

7 In Georgia, the Saakashvili administration sought to tackle petty corruption in the aftermath of the Rose Revolution by, among other approaches, institutionalising the additional costs users were willing to pay to expedite their transactions by allowing for more expensive fast-tracking in certain bureaucratic processes. 


\section{Harnessing informal networks for anti-corruption}

As this Policy Brief and the related research show, social capital works well to enable the members of informal networks to achieve illicit goals. Can this social capital be put to the service of inclusive and collective goals, including reducing corruption? Anti-corruption scholars and practitioners are starting to develop innovative approaches to combat corruption that rely on this idea.

Some social norms are associated with informal networks that drive corrupt behaviours, such as maintaining solidarity among network members and reciprocating favours received. Targeting these can help complement or bolster other initiatives (like the ones described above) to tackle the underlying factors fuelling corruption. ${ }^{8}$

Strong norms of reciprocity can be useful to operationalise multi-stakeholder (Collective Action ${ }^{9}$ ) initiatives aimed at fighting corruption. For example, they can help to build the trust needed for Integrity Pacts involving the private sector and government to get off the ground. Businesses facing extortive networks can get together and form a "good" network to denounce corruption by "dark" networks. Personal relationships can help cultivate constructive engagement between anti-corruption authorities and non-governmental organisations, where finger-pointing and mistrust often preclude effective collaboration. "Brokers" can help to connect different stakeholders and build trust in support of anti-corruption initiatives. ${ }^{10}$

Alternatively, anti-corruption practitioners can consider working with existing social networks (for instance local cooperatives) that are effective and valued by citizens

8 An ongoing GI-ACE-funded research project of the Basel Institute on Governance seeks to harnesses informal social networks and social norms of reciprocity to reduce bribery and favouritism in the Tanzanian health sector. It comprises an anti-bribery intervention that works with health workers, as well as with trusted community-based social networks, to deliver messages of attitudinal and behavioural change aimed at addressing the social acceptability of bribery and gift-giving in the provision of health services in public facilities.

9 For more information, please visit the B20 Collective Action Hub.

10 Ukraine's Business Ombudsman Council is a good example of introducing efficient ways to resolve business-related disputes between the public and private sectors. and promote the adoption of concrete anti-corruption activities to benefit their communities. Communityrooted networks generate invaluable social capital that could plausibly be harnessed to empower communities to stand up against corruption.

\section{Lessons for practitioners}

$\rightarrow$ Difficult access to public services and an uneven playing field drives ordinary citizens and business people to build informal networks through connections and corruption.

$\rightarrow$ Anti-corruption interventions should consider such networks, as opposed to narrowly focusing on the (monetary) incentives of individuals to engage in corrupt acts.

$\rightarrow$ Informal networks connecting citizens / business people and public officials are strong because they are highly functional in constrained environments. In such contexts, simply introducing more rules can actually increase corruption, because it increases the number of people that need to be co-opted and bribed.

$\rightarrow$ Overall, anti-corruption initiatives that focus on problem-solving may be more effective than simply imposing a normative standard.

$\rightarrow$ Addressing hurdles in accessing public services or government contracts can be a way to tackle corruption both from the demand and the supply sides.

$\rightarrow$ Complementing this with interventions that harness informal networks for anti-corruption can target the underlying drivers of corruption. Important social norms that govern the networks, including solidarity and reciprocity, can be targeted in support of anti-corruption. Anti-corruption Collective Active initiatives can help bring multiple stakeholders together in a "network of the good" to tackle corruption. 


\section{References}

- Baez Camargo, Claudia, Jacopo Costa, and Lucy Koechlin. 2021. “Informal networks as investment in East Africa." Global Integrity Anti-Corruption Evidence Programme (GI-ACE).

- Baez Camargo, Claudia, Jacopo Costa, Lucy Koechlin, and Danstan Mukono. 2021. "Case studies from Tanzania: GI-ACE research on informal networks and corruption." Global Integrity Anti-Corruption Evidence Programme (GI-ACE).

- Baez Camargo, Claudia, Jacopo Costa, Lucy Koechlin, and Robert Lugolobi. 2021. "Case studies from Uganda: GI-ACE research on informal networks and corruption." Global Integrity AntiCorruption Evidence Programme (GI-ACE).

\section{Keywords}

\section{Informal networks}

Corruption

Anti-corruption evidence

Collective action

East Africa

\section{About this Policy Brief}

This publication is part of the Basel Institute on Governance Policy Brief series, ISSN 2624-9669. It is licensed under a Creative Commons Attribution-NonCommercial-NoDerivatives 4.0 International License (CC BY-NC-ND 4.0). The Policy Brief presents findings from a research project entitled "Harnessing informality: Designing anti-corruption network interventions and strategic use of legal instruments" funded by UK Aid as part of the Global Integrity Anti-Corruption Evidence Programme (GI-ACE).

Suggested citation: Baez Camargo, Claudia, Jacopo Costa, and Saba Kassa. 2022. Informal networks and what they mean for anti-corruption practice. Policy Brief 9, Basel Institute on Governance.

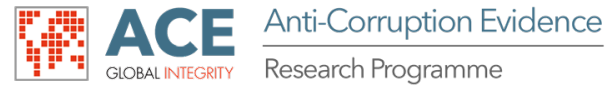

The Basel Institute on Governance is an Associated Institute of the University of Basel.

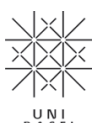

